medical attendant can bring into action. I would, therefore, recommend that in all cases of convulsions in children cutting their teeth, particularly where the cause is obscure, to lance the gums freely, since we are ignorant, according to $\mathbf{D r}$. Hugh Ley, at what time dentition commences, and consequently to produce irritation in the system.

Then, with respect to the causes of the disease, Mr. Rees and Dr. Marshall Hall are at issue again; the former believing enlargement of the thymus gland to be a cause, and the latter to be the effect of it. Upon this point I am inclined to agree with the latter gentleman from the post-mortem appearances of the body of a child which died under my own care.

A little girl of the name of Smith, three years of age, residing at 62 , Curtain-road, was brought to my house suffering from enlargement of the spleen. She died subsequently of acute bronchitis induced by hooping-cough. On opening the body, the spleen was found enormously enlarged, extending in length from the diaphragm into the left iliac fossa, and in breadth from the vertebra to the navel; the liver was nearly double the average size, and the thymus gland was as large as a hen's egg. In this case there was not either crowing inspiration nor convulsions during the time that she was under my treatment. The last point which I shall notice in Mr. Rees's letter is the following; Marshall Hall in proving his position, that the thymus gland is enlarged by the convulsive efforts caused by the closing of the rima glottidis, cites a case which he witnessed where the thyroid gland had been permanently enlarged "from the efforts of severe and protracted parturition."

Now, Mr. Rees, in attempting to subvert this doctrine, says, " that there is no analogy between enlargement of the thyroid, and hypertrophy of the thymus gland," as the former is so well supplied with blood, that he has seen it "swell at each catamenial period," such not being the case with the latter, it being a conglomerate gland. He then adds, that "for Dr. Hall's arguments to have any veight, it would be necessary for him to adduce instances where the parotid or submaxillary glands had become enlarged from any temporary excitement or cerebral congestion." Now, I shall supply for Mr. Rees's satisfaction the possibility of the submaxillary and cervical glands becoming enlarged under such circumstances. F. D., my own child, a boy four year's and a half old, of light hair, blue eyes, and fair complexion, has never had tits of any description in his life until about six months ago. He then had two, in consequence, we presinme, of over-feeding.: The first fit produced enlargement of one of the glands in the lumbar region; and the second, which happened about a week afterwards, caused swelling of the submaxillary gland, and of one of the cervical glands just above the clavicle. These glands inflamed and suppurated, and the cicatrices remain to this day. It is my opinion, therefore, that in the majority of cases where the thymus gland is found enlarged after death from this disease, it is caused by the convulsive efforts; and is it not feasible that it should be so? Do we not find effusion of blood into the eyelids frequently from epilepsy? Do we not find con? gestion of the whole glandular system take place from obstructed circulation through the lungs; and is it not more than probable that the strangulation, which is the ehief symptom of this disease, and the consequent obstructed circulation through the lungs in consequence of the exclusion of the atmosphere, produces the same state of things; and that every organ behind the right ventricle of the heart becomes congested, and amongst the rest the thymus gland?

Apologising to Mr. Rees for making so free with his name, and assuring him that nothing but the elicitation of truth induced me to do so ; and apologising to you, Sir, for the length to this article, I beg to subscribe myself your obedient servant,

R. Davis, M.R.C.S.

Worship-square, Aug. 16, 1842.

\section{LARYNGISMUS STRIDULUS.}

JANET M'NIVEN, aged two years and a half, had been treated three weeks for laryngismus stridulus, by her parents, withont success. The crowing fit came on every evening at about seven o'clock, and continued from five to twelve hours. There was a hoarseness throughout the day, with no $\mathrm{cm}$. barrassment of breathing. The fit, although lasting long, was never altogether so violent as to deprive the child entirely of sleep. In other respects she was in good health, perhaps a little paler than usual. A blister was applied to the throat, and small doses of calomel and Dover's powder were administered throughout the day. For two nights this plan was successful, so far that although the crowing was still present, it was of a mitigated character. On the third night she was worse than she had ever been, the crowing amounting almost to suffocation. On the fifth night the spine was rubbed with opium liniment, containing a drachm of croton oil. In three hours afterwards a rash appeared on the parts rubbed, which was so very considerable next morning, that it was not rubbed a second time. In the night the child's spine was rubbed with the croton oil liniment. She passed a good night, entirely free from the crowing, and has remained quite well ever since (now eight days), without further treatment, or medicine of any kind whatever. W. HENDERSON, M.D.

Corstorphine, Edinburgh, Aug. 15, 1842 . 